\title{
A patient with 47, XYY mosaic karyotype and congenital absence of bilateral vas deferens: a case report and literature review
}

\author{
Ci Zou*, Dexin Yu, Hao Geng, Xiaofeng Lan and Wei Sun
}

\begin{abstract}
Background: The incidence of 47, XYY syndrome in live-born male infants is 1/1000. Due to its variable clinical symptoms, the diagnosis is easy to miss. The incidence of congenital bilateral absence of the vas deferens (CBAVD) in infertile men is $1-2 \%$. The main cause is the mutation of CFTR and ADGAG2 genes.

Case presentation: The patient was a 33-year-old man who visited a doctor 5 years ago due to infertility. The investigation revealed that the patient's secondary sexual characteristics, testicular, and penis development were normal, and there was no gynecomastia, but the bilateral vas deferens and epididymis were not palpable. Transrectal ultrasound showed that the left seminal vesicle was missing, and the right seminal vesicle was atrophied. No abnormality was observed in $Y$ chromosome microdeletion. Karyotype analysis indicated that the patient was 46, XY/47, XYY mosaic. Genetic testing found heterozygous mutations at two sites of CFTR (c263T> G and c2249C>T).
\end{abstract}

Conclusions: Herein, we report the rare case of a male patient with clinical manifestations of infertility, chromosome $46, X Y / 47, X X Y$ mosaic type, simultaneously manifested as the absence of bilateral vas deferens. Two pathogenic heterozygous CFTR gene mutations were found. Given the low genetic risk of the disease, we recommend that patients undergo intracytoplasmic sperm injection (ICSI) for fertility assessment.

Keywords: 47, XYY syndrome, Ongenital absence, Bilateral vas deferens, Case report

\section{Background}

The 47, XYY syndrome often has impaired neurocognitive function, manifested as language barriers, behavioral abnormalities, and decreased motor ability and ability to receive an education. Studies have found that, compared to the normal population, men with $47, \mathrm{XYY}$ syndrome often have other diseases simultaneously and are prone to health problems [1]. Therefore, timely diagnosis of diseases, prediction of comorbidities, and in-depth clinical evaluation and consultation of patients in a multidisciplinary joint will help to improve the long-term health prognosis of patients with $47, \mathrm{XYY}$ syndrome. Although

*Correspondence: zci2003@qq.com

Department of Urology, The Second Affiliated Hospital of Anhui Medical

University, No. 678 Furong Road, Hefei 230601, China most patients can give birth typically, it is necessary for patients with 47, XYY syndrome to have receive genetic counseling for prenatal and postnatal care and reduce genetic risk.

Congenital bilateral absence of the vas deferens (CBAVD) is considered to be the primary manifestation of cystic fibrosis (CF) in the reproductive system, accounting for $1-2 \%$ of the causes of male infertility [2, 3]. Mutations in CFTR and ADGRG genes are the primary pathogenesis of the disease [4]. There is at least one slight mutation in the CFTR gene in European whites with CBAVD, but mutations are relatively rare among Chinese. Mutations in the CFTR gene show significant ethnic differences. The most common among Caucasian people is the F508 $\delta$ mutation, while the most common among Chinese is the I556V mutation [5-7]. CBAVD 
can be accompanied by many complications, such as the absence or dysplasia of the kidneys and seminal vesicles; dilatation of the epididymis; and absence of different parts of the epididymis; dysplasia of the ejaculatory ducts; inguinal hernias, etc.

Here, this article reports a rare case of CBAVD with 46, $\mathrm{XY} / 47$, XYY heterozygous, and two heterozygous CFTR gene mutations.

\section{Case presentation}

The patient was a 33-year-old man who visited a doctor 5 years ago due to infertility. He had a normal sexual desire and sexual life and denied having a positive family history and other diseases. Physical examination revealed that he was in standard shape (height $172 \mathrm{~cm}$, weight $73 \mathrm{~kg}$ ), and his body mass index was $24.6 \mathrm{~kg} / \mathrm{m}^{2}$. The investigation revealed that the patient's secondary sexual characteristics, testicular, and penis development were normal, and there was no gynecomastia, but the bilateral vas deferens and epididymis were not palpable. Two independent semen analyses confirmed that the patient was azoospermic. Testosterone, luteinizing hormone, follicle-stimulating hormone (FSH), and prolactin levels in the morning were normal. Ultrasound revealed that the volume of both testes was normal; however, the tails of the epididymis were absent. Transrectal ultrasound showed that the left seminal vesicle was missing, and the right seminal vesicle was atrophied (Fig. 1). No abnormality was observed in Y chromosome microdeletion. Karyotype analysis indicated that the patient was 46, XY/47, XYY mosaic (Fig. 2). Genetic testing found heterozygous mutations at two sites of CFTR (c263T > G and $\mathrm{c} 2249 \mathrm{C}>\mathrm{T}$ ). Some sperms were discovered via a testicular puncture (Fig. 3). Given the low genetic risk of the
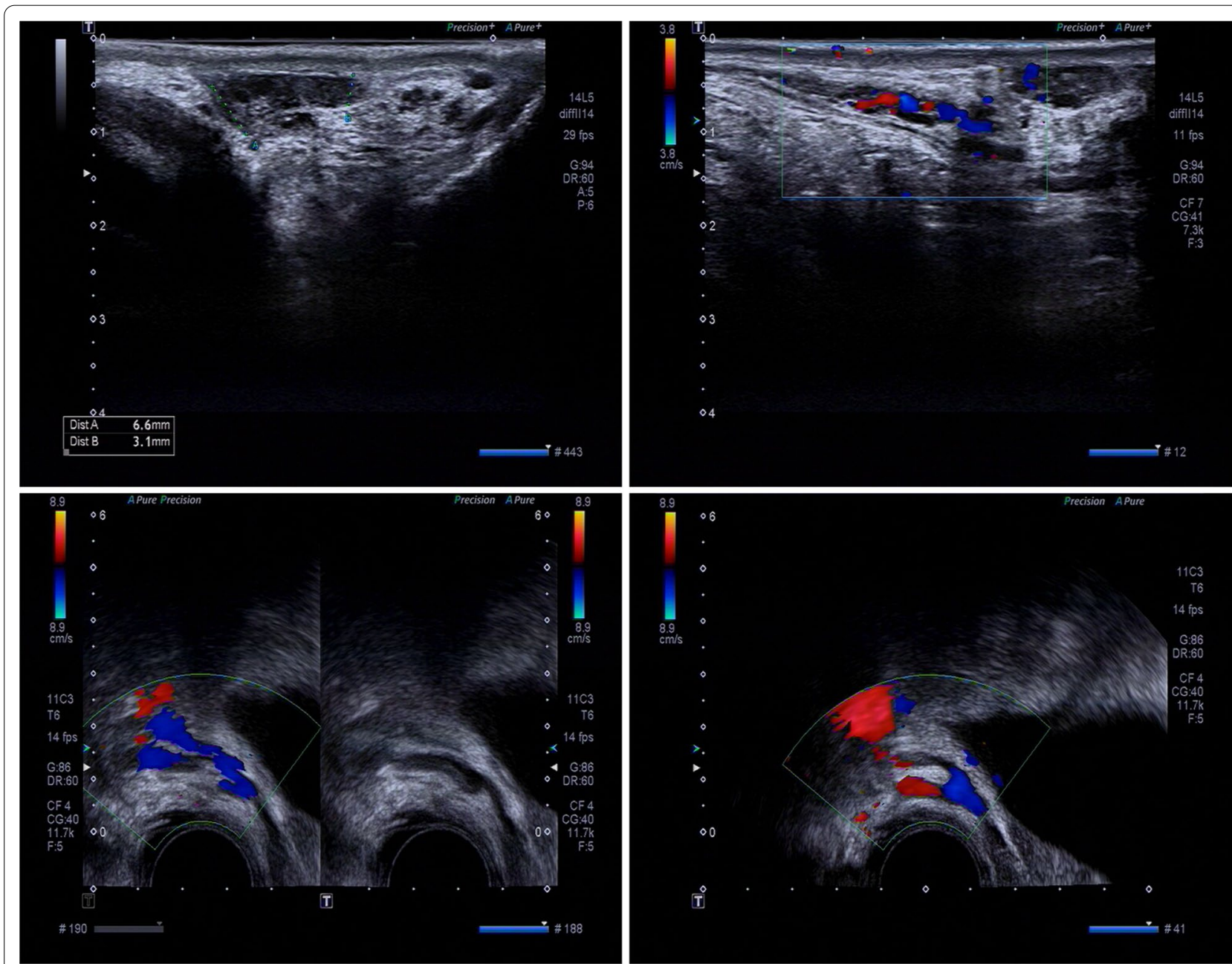

Fig. 1 Scrotal and transrectal ultrasonography revealed the absence of the tail of epididymide, vas deferens and seminal vesicle on the right side, and dysplastic seminal vesicle on the left side 


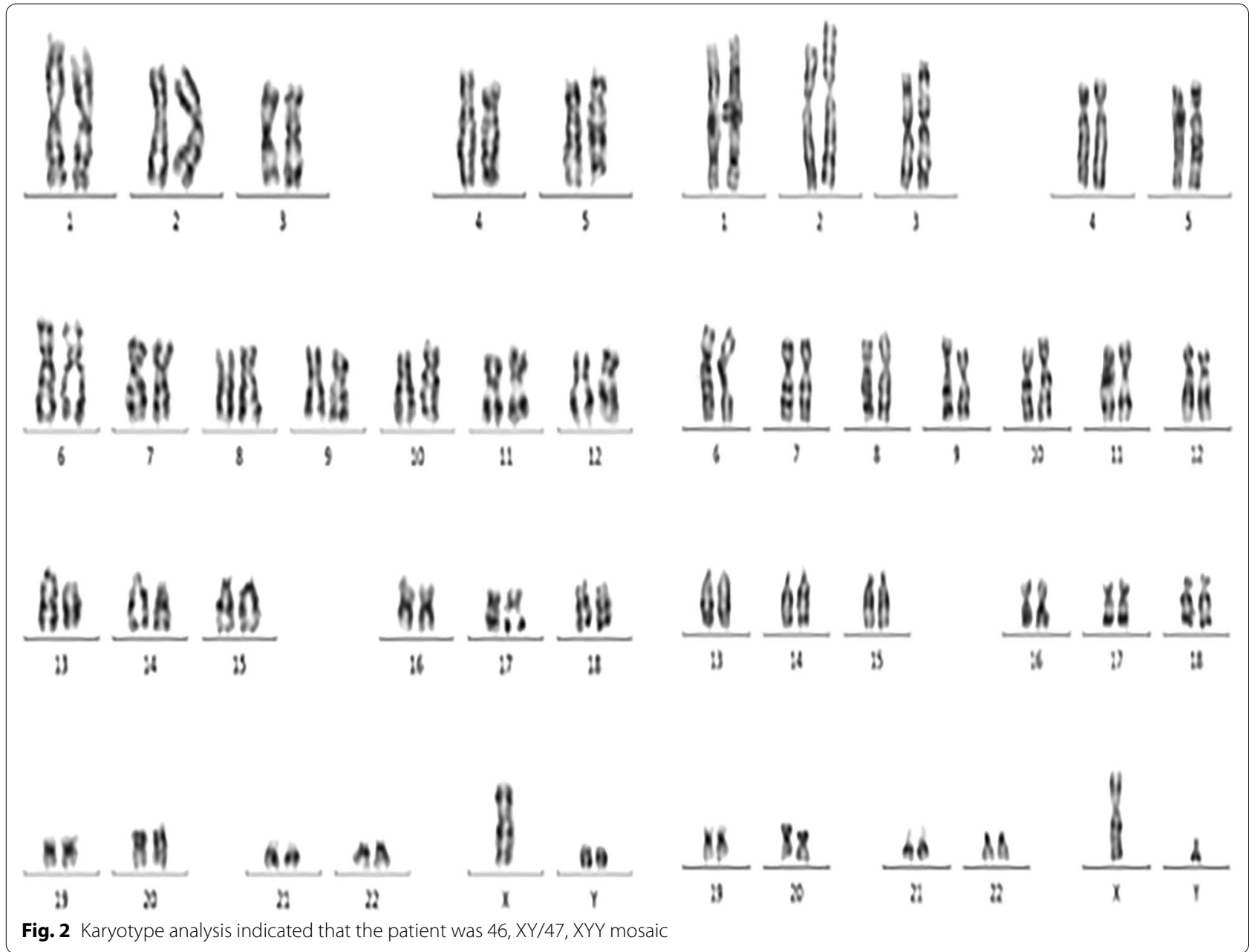

disease, we recommend that patients undergo intracytoplasmic sperm injection (ICSI) for fertility assessment.

\section{Discussion and conclusions}

Due to the atypical symptoms of $47, \mathrm{XYY}$ syndrome, approximately $85 \%$ of patients are not diagnosed until they develop infertility [8]. Most patients experienced undiagnosed in the fetus and at birth, often with delayed or missed diagnosis. It is currently believed that 47 , XYY syndrome is caused by the unsegregation of $\mathrm{Y}$ chromosomes during meiosis II or mitosis after the formation of zygotes. In theory, X, Y, XY, YY should be observable in the sperm of such patients, and there should be a $50 \%$ chance of abnormal karyotypes occurring in their offspring. However, studies have reported that chromosomal abnormalities are rare in the offspring of such patients, and the incidence is less than $1 \%[9,10]$. Although the risk of infertility for this syndrome is four times higher than that of ordinary men, most patients are fertile. The reason for this phenomenon is believed to be the loss of the extra Y chromosomes before mitosis. The animal model that sterile triploid chromosome mice can obtain fertile offspring through the phenomenon of "trisomy bias chromosome loss" also strongly supports this view [10]. Studies have shown that the sperm count of patients with $47, \mathrm{XYY}$ syndrome is uncertain, and the sperm count ranges from average to azoospermia $[9,11]$. Moreover, 46, XY/47, XYY chimera can produce normal sperm; most people are fertile, as we reported in this patient. Only a few patients experience fertility difficulties. Regarding these patients, percutaneous epididymal sperm aspiration (PESA) and intracytoplasmic sperm injection (ICSI) may help increase their fertility. The in vitro fertilization and embryo cleavage rates are high, and the fetuses born are also very healthy $[9,10]$.

CBAVD is usually found due to infertility or surgery. Its diagnostic criteria are standard or small testicular volume, untouchable vas deferens, normal seminal FSH level, and low semen volume $(<1 \mathrm{~mL})$. Semen has the following characteristics: no sperm; acidic $\mathrm{pH}$; 

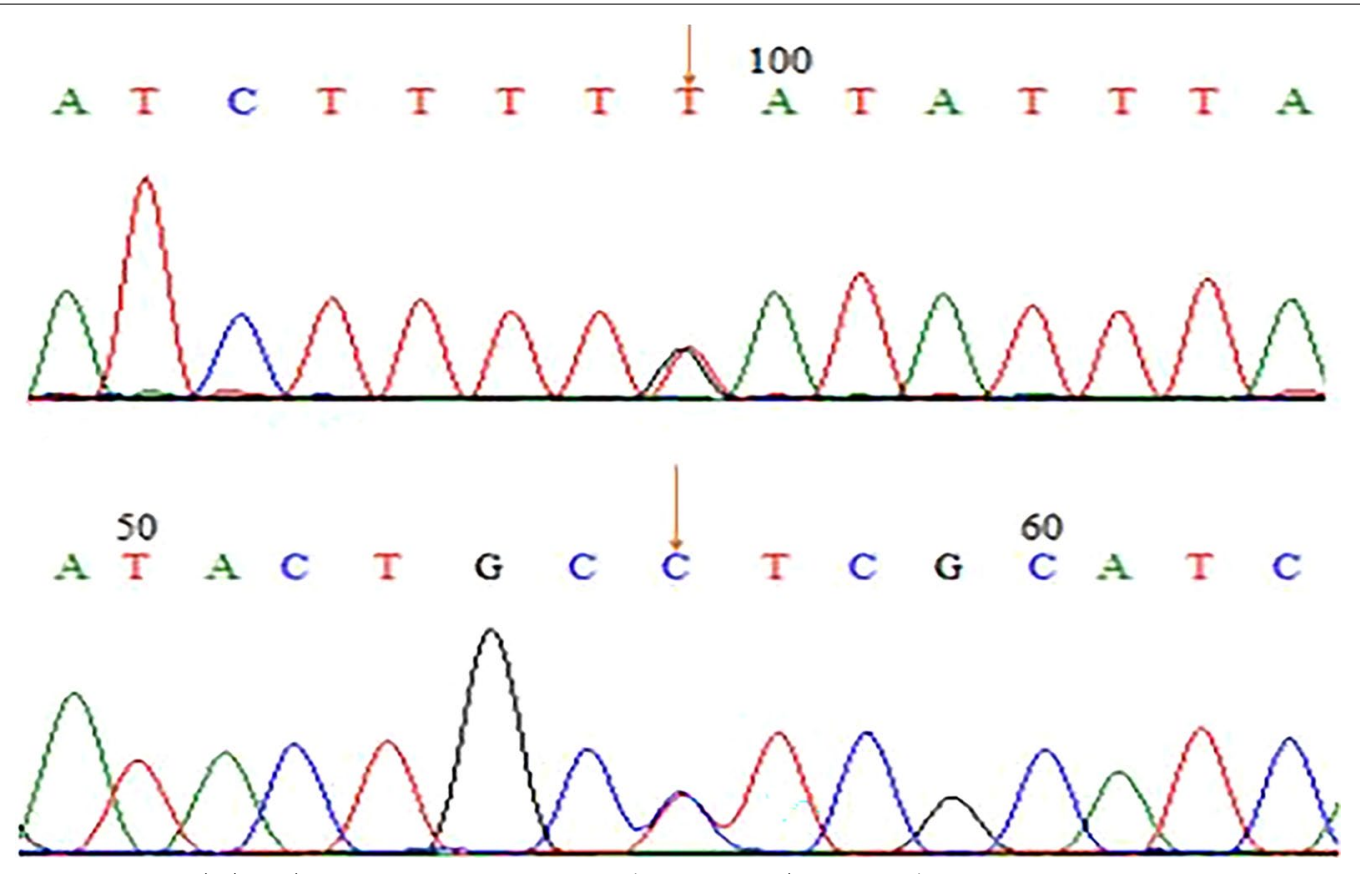

Fig. 3 Gene sequencing revealed two heterozygous CFTR mutations (c263T > G and c2249C >T)

undetectable fructose or low concentration. Studies have found that the incidence of seminal vesicle abnormalities such as absence, dysplasia, or cystic dysplasia in patients with CBAVD is as high as 36-92\% [11-13]. Furthermore, studies have reported that $11-21 \%$ of patients with CBAVD have renal absences. As both the male reproductive and urinary systems originate from the mesorenal tube, the two are closely related in embryology and anatomy, which explains why malformations of the reproductive system are often associated with renal malformations [14].

CBAVD is considered an atypical manifestation of CF. Approximately $95 \%$ of patients with CF who only exhibit CBAVD have CFTR gene mutations. In Chinese patients, the mutation frequency of CFTR is $12.7 \%$, and $1556 \mathrm{~V}$ is the most common type of mutation [6, 15]. The mutation spectrum is $5 \mathrm{~T}$, p. Ile556Val, and p. Gln1352His (mutant allele counts are 175, 65, and 19, respectively). The most common type of mutation is a heterozygous mutation, which is significantly different from European races. Two-thirds of Caucasian CBAVD patients were identified having CFTR mutation associated with $C F$, but those mutations were reported to be rare in Chinese men. Besides, Caucasian patients had higher F508del mutation frequency, but I556V was the most common mutation in Chinese CBAVD patients [5-7]. In this case, two mutations, p.L88X and p.P750L, were found. These two mutations are not rare, but they are pathogenic.
Studies have shown that sperm production is impaired in patients with CBAVD, the risk of miscarriage and stillbirth is significantly increased, and the live birth rate is reduced considerably $[5,16]$. However, many patients can produce their offspring through PESA and ICSI. To our knowledge, this article reports the first case of infertility with sex chromosomal abnormalities combined with autosomal gene mutations. Regarding eugenics, prenatal genetic counseling is necessary for both CBAVD and 47, XYY syndrome.

In conclusion, we reported a rare case who is a congenital absent of bilateral vas deferens (CBAVD) infertile patient, concomitant with 46, XY/47, XYY mosaic karyotype. Given the low genetic risk of the disease, we recommend that patients undergo intracytoplasmic sperm injection (ICSI) for fertility assessment. Genetic counseling is necessary for patients with either CBAVD or 47, $\mathrm{XYY}$ karyotype in their pursuit of parenthood.

\section{Abbreviations}

CBAVD: Congenital bilateral absence of the vas deferens; CF: Cystic fibrosis; FSH: Follicle-stimulating hormone; PESA: Percutaneous epididymal sperm aspiration; ICSI: Intracytoplasmic sperm injection.

\section{Acknowledgements}

We would like to thank Editage (www.editage.cn) for English language editing.

\section{Authors' contributions}

ZC and YD conceived and designed the study, HG collected and compiled the data, and XL and WS analyzed and interpreted the data. All authors participated in the drafting of the manuscript or critically revised important 
intellectual content, and all authors have read and finally approved the forthcoming version.

\section{Funding}

No funding.

\section{Availability of data and materials}

The datasets generated and/or analysed during the current study are available in the figshare repository, https://doi.org/10.6084/m9.figshare.18972914.v1.

\section{Declarations}

\section{Ethics approval and consent to participate}

This study was approved by the Ethics Committee of the Second Affiliated Hospital of Anhui Medical University, and the patient's informed written consent was obtained for publication of this manuscript and any accompanying images.

\section{Consent for publication}

Written informed consent was obtained from the patient and his family for the publication of this manuscript and any accompanying images.

\section{Competing interests}

The authors declare that they have no competing interests.

Received: 23 October 2021 Accepted: 26 January 2022

Published online: 02 February 2022

\section{References}

1. Berglund A, Stochholm K, Gravholt CH. Morbidity in 47, XYY syndrome: a nationwide epidemiological study of hospital diagnoses and medication use. Genet Med. 2020;22(9):1542-51.

2. Jarzabek K, Zbucka M, Pepiński W, Szamatowicz J, Domitrz J, Janica J, Wołczyński S, Szamatowicz M. Cystic fibrosis as a cause of infertility. Reprod Biol. 2004;4(2):119-29.

3. Anguiano A, Oates RD, Amos JA, Dean M, Gerrard B, Stewart C, Maher TA, White MB, Milunsky A. Congenital bilateral absence of the vas deferens. A primarily genital form of cystic fibrosis. JAMA. 1992;267(13):1794-7.

4. Yuan P, Liang ZK, Liang H, Zheng LY, Li D, Li J, Zhang J, Tian J, Lai LH, Zhang $\mathrm{K}$, et al. Expanding the phenotypic and genetic spectrum of Chinese patients with congenital absence of vas deferens bearing CFTR and ADGRG2 alleles. Andrology-US. 2019;7(3):329-40.

5. Lu S, Cui Y, Li X, Zhang H, Liu J, Kong B, Cai F, Chen ZJ. Association of cystic fibrosis transmembrane-conductance regulator gene mutation with negative outcome of intracytoplasmic sperm injection pregnancy in cases of congenital bilateral absence of vas deferens. Fertil Steril. 2014; 101(5):1255-60

6. Lu S, Yang X, Cui Y, Li X, Zhang H, Liu J, Chen ZJ. Different cystic fibrosis transmembrane conductance regulator mutations in Chinese men with congenital bilateral absence of vas deferens and other acquired obstructive azoospermia. Urology. 2013;82(4):824-8.

7. Yu J, Chen Z, Ni Y, Li Z. CFTR mutations in men with congenital bilateral absence of the vas deferens (CBAVD): a systemic review and meta-analysis. Hum Reprod. 2012;27(1):25-35.

8. Bardsley MZ, Kowal K, Levy C, Gosek A, Ayari N, Tartaglia N, Lahlou N, Winder B, Grimes S, Ross JL. 47, XYY syndrome: clinical phenotype and timing of ascertainment. J Pediatr. 2013;163(4):1085-94.

9. Martin $\mathrm{RH}$, Shi Q, Field LL. Recombination in the pseudoautosomal region in a 47, XYY male. Hum Genet. 2001;109(2):143-5.

10. Zhang X, Liu X, Xi Q, Zhu H, Li L, Liu R, Yu Y. Reproductive outcomes of 3 infertile males with $X Y Y$ syndrome: Retrospective case series and literature review. Medicine (Baltimore). 2020;99(9):e19375.

11. Shi $\mathrm{Q}$, Martin RH. Multicolor fluorescence in situ hybridization analysis of meiotic chromosome segregation in a 47, XYY male and a review of the literature. Am J Med Genet. 2000;93(1):40-6.

12. Samli H, Samli MM, Yilmaz E, Imirzalioglu N. Clinical, andrological and genetic characteristics of patients with congenital bilateral absence of vas deferens (CBAVD). Arch Androl. 2006;52(6):471-7.
13. Casals T, Bassas L, Egozcue S, Ramos MD, Giménez J, Segura A, Garcia F, Carrera M, Larriba S, Sarquella J, et al. Heterogeneity for mutations in the CFTR gene and clinical correlations in patients with congenital absence of the vas deferens. Hum Reprod. 2000;15(7):1476-83.

14. Jarvi K, McCallum S, Zielenski J, Durie P, Tullis E, Wilchanski M, Margolis M, Asch M, Ginzburg B, Martin S, et al. Heterogeneity of reproductive tract abnormalities in men with absence of the vas deferens: role of cystic fibrosis transmembrane conductance regulator gene mutations. Fertil Steril. 1998;70(4):724-8.

15. van den Ouden D, Blom JH, Bangma C, de Spiegeleer AH. Diagnosis and management of seminal vesicle cysts associated with ipsilateral renal agenesis: a pooled analysis of 52 cases. Eur Urol. 1998;33(5):433-40.

16. de Souza D, Faucz FR, Pereira-Ferrari L, Sotomaior VS, Raskin S. Congenital bilateral absence of the vas deferens as an atypical form of cystic fibrosis: reproductive implications and genetic counseling. Andrology-US. 2018;6(1):127-35

17. Meng MV, Black LD, Cha I, Ljung BM, Pera RA, Turek PJ. Impaired spermatogenesis in men with congenital absence of the vas deferens. Hum Reprod. 2001;16(3):529-33.

\section{Publisher's Note}

Springer Nature remains neutral with regard to jurisdictional claims in published maps and institutional affiliations.
Ready to submit your research? Choose BMC and benefit from:

- fast, convenient online submission

- thorough peer review by experienced researchers in your field

- rapid publication on acceptance

- support for research data, including large and complex data types

- gold Open Access which fosters wider collaboration and increased citations

- maximum visibility for your research: over $100 \mathrm{M}$ website views per year

At BMC, research is always in progress.

Learn more biomedcentral.com/submissions 